MedieKultur | Journal of media and communication research | ISSN 1901-9726

Article

\title{
Digitising migration heritage: A case study of a minority museum
}

\section{Randi Marselis}

MedieKultur 2011, 50, 84-99

Published by SMID | Society of Media researchers In Denmark | www.smid.dk The online version of this text can be found open access at www.mediekultur.dk

Museums are increasingly digitising their collections and making them available to the public on-line. Creating such digital resources may become a means for social inclusion. For museums that acknowledge migration history and cultures of ethnic minority groups as important subjects in multiethnic societies, digitisation brings new possibilities for reaching source communities. This article presents Web projects conducted at Museum Maluku in Utrecht, the Netherlands. The article focuses on the museum's experiences with cross-institutional Web projects, since digitisation of the museum's collection was initiated through collaboration with major national heritage institutions. These collaborative projects furthermore have raised the visibility of Dutch-Moluccans as a part of Dutch national history. The article also discusses how source communities through digital participation can become involved in building cultural heritage. Based on the case study of the Museum Maluku, it is argued that in order to design an appropriate mode of user participation as well as a sense of ownership, it is crucial to take memory politics of source communities into account. 


\section{Digital heritage and source communities}

Museums in Western Europe are challenged by increased cultural diversity within the populations that make up their potential audiences, and especially museums of cultural history are now acknowledging cultures of ethnic minority groups as an important subject in multiethnic societies. Some museums are specialised in migration history, while others are large cultural museums that own collections originating from groups that used to live faraway and could be represented as exotic Others, but who due to migration processes have become present in the immediate context of the museum. For both types of museums, it has become crucial to reach source communities defined as "groups in the past when artefacts were collected, as well as their descendants today" (Peers \& Brown, 2003, p. 2). Working with source communities implies a two-way information process in which groups are given access to memory materials and the expertise of museum staff, but are at the same time recognised as able to contribute with valuable perspectives on their own culture (ibid., p. 1).

The digitisation of collections that is presently taking place at numerous museums offers new possibilities for collaboration with source communities, and the Web medium is well suited for making such projects accessible to the public. In a recent article, Andrew Flinn describes a number of projects where museums and archives use social and participatory software for "harnessing and sharing community knowledge" (2010, p. 43). It becomes clear from Flinn's article that digital user participation can take many forms and is not necessarily well described by the terms user generated content or co-creation, which could be said to imply a creative contribution from users. In this article, I have chosen an analytical distinction between three types of user participation, co-collection, co-interpretation and cocreation, although in praxis these will often be intertwined. In relation to source communities, co-collection is about collecting memory materials and factual information about the communities in question, while co-interpretation refers to the process of ascribing meaning to such memory materials, which is likely to initiate debate due to memory politics within the communities. The term co-creation will be reserved for processes in which users are involved in creating new material that might or might not make use of memory materials already in the collection.

This article focuses on a small, private, minority museum, Museum Maluku (MuMa) in Utrecht, the Netherlands, comprising the history and culture of the Dutch-Moluccan community. In recent years, MuMa's staff, with the help of interns and volunteers, has carried out several digitising projects in order to make the museum's extensive collection of memory materials accessible to Dutch-Moluccans as well as to the general public. Since the museum is small and has limited resources, both in terms of finances and staff, it has been important to find external funding, and digital Web projects have typically been carried out in cooperation with other cultural institutions and/or been financed as part of broader national memory programs (for instance about Dutch heritage from the Second World War). It is not possible within the scope of this article to describe all the digital Web projects 
made by MuMa, so I will focus on projects that illustrate the benefits and disadvantages of cross-institutional collaboration. Furthermore, the projects chosen are especially interesting in relation to co-collection, since they exemplify how a small museum with simple technological means, such as email and reaction forms, can collaborate with source communities to build digital heritage.

The museum was not chosen as a case because it makes use of the most advanced types of participatory technologies, but rather because it has a tradition of working with the source community and of taking memory politics and sensitivities of this community into consideration. As a minority museum, Museum Maluku aims at creating dialogue between the Dutch-Moluccan minority and other groups in Dutch society. Representing (post)colonial history at museums can at times become extremely sensitive and might even evolve into conflict (Stevens, 2007). For this reason, it is especially important to focus attention on museums that have successfully thematised such sensitive topics and gained the trust of source communities. However, as pointed out by Laura Peers and Alison K. Brown, many museums have taken on the challenge of collaborating with source communities, "but only some museums - the larger ones, and often the university museums - will have the staff resources and impetus to publish about their projects and experiences" (2003, p.15). For this reason, it is important that researchers, who are not affiliated with a particular museum, take the time to examine what is being accomplished by small minority museums like Museum Maluku.

\section{The Moluccan minority in the Netherlands ${ }^{2}$}

The Moluccas (Maluku) are situated in the Malay Archipelago, and the islands are today part of Indonesia. The islands have historically been known as the Spice Islands, since both nutmeg and clove trees are native to the islands. For many centuries, Chinese and Arabic merchants traded in spices from the islands before the Portuguese arrived, soon followed by other European trading companies. After being at war with native inhabitants as well as the other European colonial powers, the Dutch obtained control over the area during the 17th century and subsequently the islands became part of the colony Dutch East Indies. From the last decennials of the 19th century, an increasing number of Moluccan men were enrolled in the colonial army, KNIL (Koninklijk Nederlands Indisch Leger), where they were preferred by the colonial administration, as many Moluccans were Christians. Both in their own perception and amongst the Dutch population, Moluccan soldiers got the reputation of being highly skilled soldiers, who furthermore had been loyal to the Netherlands for centuries. Moluccan-KNIL soldiers fought on the Dutch side against Japanese troops in the Second World War as well as against Indonesian independence between 1945 and 1949. The Netherlands was then forced to acknowledge Indonesia and the KNIL army was going to be demobilised. However, new developments on the Moluccas would have important consequences for the KNIL soldiers and their families, who were stationed in camps throughout 
the entire Indonesian region. In April 1950, the independent Republic of the South Moluccans (RMS: Republik Maluku Selatan) was proclaimed, since especially Christian inhabitants of the Moluccas were concerned about becoming a minority in a centralised, Muslim, Indonesian state. However, Moluccan independence was unacceptable to the Indonesians, and by December 1950, the Indonesian army had occupied the islands, although a guerrilla war would continue for many years, and the political fight for an independent RMS is to some extent still going on.

Most Moluccan-KNIL soldiers sympathised with the RMS, and wished to return to the Moluccas, but Indonesia would not allow these trained soldiers to return to the islands. This became a huge problem for the Dutch government, since according to KNIL rules the soldiers had the right to demobilise in a location of their own choice. In the end, the Dutch government decided to ship the Moluccan soldiers and their families to the Netherlands for a limited period of time. In 1951, around 12,500 Moluccans were transported to the Netherlands and the soldiers were discharged on arrival. The Moluccans were placed in camps throughout the country and a policy of segregation was maintained until the 1960s, since both the Moluccans themselves and the Dutch authorities awaited the possibility of repatriation. The Moluccans expected the Dutch government to actively support the ongoing political fight for an independent Republic of the South Moluccans (RMS), but this did not happen due to the international political situation. In the late 1960s and the 1970s, groups amongst the second generation, who had grown up in the camps, radicalised in their fight for RMS and their anger towards the Dutch government. A series of violent actions followed. These actions culminated in a double hijacking of a train and a primary school in 1977. In the train hijacking, both hostages and hijackers were killed. After these events, support for radical actions dwindled amongst the Moluccan community. From this point the Dutch-Moluccans became more oriented against integration in the Dutch society. Furthermore, the Dutch authorities in cooperation with Moluccan organisations undertook a series of initiatives in order to strengthen the social economic position of the Moluccans. As part of these strategies of integration, it was decided to establish a museum.

\section{Museum Maluku}

While the Dutch authorities originally proposed a monument in a park, the Moluccan representatives preferred a museum that could function as a "living monument" (Smeets \& Steijlen, 2006, p. 303). The Moluccan Historical Museum opened with governmental support in 1990 and became a private foundation in 1996. The mission of the museum is "to collect, to preserve, to research and to present the material and immaterial heritage of the Dutch-Moluccan community in the Netherlands". In 2008, the museum changed its name to Museum Maluku (MuMa) in order to stress that the museum was not only representing historical events but also concerned with current events and developments. MuMa's vision statement describes the Moluccan community as "an integral part of Dutch soci- 
ety while at the same time retaining its unique characteristics and strong ties to the area of origin, the Moluccas. The heritage of Moluccans reflects this position". 3 The museum can be said to interpret the Dutch-Moluccan community's situation as a case of simultaneity, which implies that enduring transnational ties are not incompatible with integration in the country of settlement (Levitt \& Glick Schiller, 2003). Within the community, it has become increasingly popular to visit the Moluccas as well as to support social development and human rights issues on the islands. Furthermore, parts of the community support the political fight for an independent Moluccan state (RMS). Memory politics of the community however are not unanimous, and since MuMa has to take the continuous politicisation of Dutch-Moluccan history into account, the museum aims at a neutral voice in its exhibitions and texts.

The museum building in Utrecht contains a permanent historical exhibition and a knowledge centre. Furthermore, MuMa stimulates contemporary Moluccan cultural expressions through temporary exhibitions and cultural events. The website is crucial for telling the public about exhibitions and events going on, but is also used to make users aware of media texts about Moluccans in other media. Thus, MuMa acknowledges that the memory work of the Dutch-Moluccans is going on in many different forums. Richard Sandell has proposed that museums' exhibitions should be seen as resources that exist alongside others in the broader mediascape, and that users' interpretative processes will draw on a diversity of resources (2007, pp. 24, 93). This positioning in a wider mediascape is also visible through the museum's presence on social network sites like Facebook and Hyves. It is beyond the scope of this article to conduct a thorough analysis of the museum website or its use of social network sites. Rather, this article focuses on Web projects that provide digital access to the MuMa's collection of Dutch-Moluccan heritage. I will first describe two earlier projects that were carried out in collaboration with major national heritage institutions and are hosted on their websites, before I return to current digitising projects that will be accessible through MuMa's own website.

\section{The Arrival: The database as a digital monument}

In 2001, at the 50 year commemoration of the arrival of the ships with the Moluccans, the passenger lists were exhibited and caused a great deal of interest. Based on this experience, MuMa decided to include copies of these lists in their permanent exhibition. Ships through history have become powerful symbols of migration, and finding your own or a relative's name in the passenger list is charged with emotions since it so clearly marks the physical passage of migration. ${ }^{4}$ Due to the interest amongst the Moluccan community, it was decided to build a database based on the passenger lists. This project, named The Arrival (de Aankomst), was realised in cooperation between MuMa and the Dutch National Archive (Nationaal Archief), which as a strategy of social inclusion set up special databases where members of ethnic minority groups can search for ancestors. ${ }^{5}$ Thus, the Moluccan 


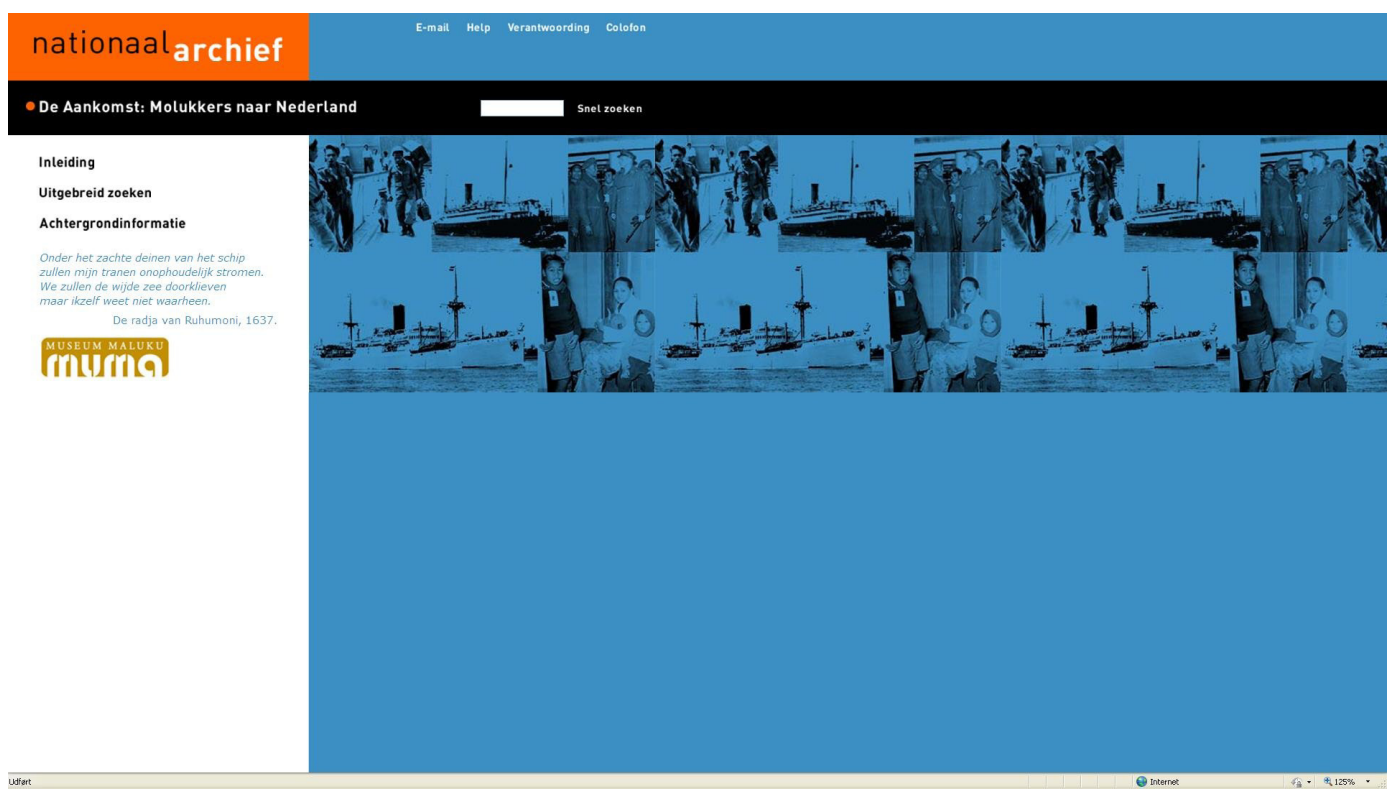

database was launched both as a tool for private family history and for professional socialhistorical research. According to the mission statement, the database was also meant to be a digital monument created as a tribute to the first generation of Moluccans in the Netherlands. In order to ensure acceptance from the Moluccan community, cultural organisations were consulted and community media, such as the magazine Marinjo, informed the public about the purpose of the database.

The database is integrated in a webpage that also includes historical background information. The aesthetic design of the webpage's front page is quite simple and follows a model also used in some of the Dutch National Archive's other databases. The dominant colour is a saturated medium blue that is used as background for a montage of old photographs. The logo of the archive is shown on an orange background that as a complementary colour to the blue creates a dynamic impression. Moreover, orange being the colour of the Dutch Royal Family (House of Orange-Nassau) connotes Dutchness and thus stresses that this is a national archive. Used for The Arrival, this design might be said to emphasise Moluccan's migration history as part of Dutch national history. The photographs show some of the ships, soldiers in uniform talking to each other, a soldier boarding the ship, while he is holding the hand of a little boy, and, most strikingly, a photograph taken through a cabin door, showing a mother with three children. The mother is holding a baby and timidly smiles in the direction of the photographer. Next to her sits a little boy with his head wrapped in a scarf as if he is cold. He looks towards the camera with a serious expression. Another boy of approximately seven years of age is standing up holding on to the door frame. He looks a bit scared and opens his mouths as if he is about to say something. His expression underlines the mode of direct address created by having three persons in the photograph looking back at the viewer. According to Günther Kress and Theo van Leeuwen, a picture 
in which the viewer is addressed directly by the gaze of the portrayed persons "conveys a sense of interaction between the depicted person and the viewer" (2006, p. 43). In this case, the photograph can be said to invite the viewer to identify with the uncertain situation of the arriving Moluccans. That these historical events were bewildering is furthermore underlined by lyrics from an old Moluccan song placed to the left of the photographs:

\author{
During the soft rolling of the ship \\ my tears will ceaselessly flow \\ We shall plough through the wide sea \\ but I myself do not know where to \\ The radja van Ruhumoni, 1637 \\ (author translation)
}

The song refers to the historical past and suffering of the Moluccans, since it describes the feelings of the radja as he was transported to the prison island Onrust near Batavia after having fought against the Dutch colonisers (Lilipaly-de Voogt, 1993, p. 318). The rather simple design of the front page is thus modified in a way that keeps to the style of the national archive but at the same time subtly acknowledges that the memories of the Moluccan's arrival to the Netherlands are still emotionally charged.

In the database it is possible to search on family name, ship, birthday and soldier number. the original passenger lists grouped arrivals according to families. However, the lists did not include much information about women and children. The soldiers were listed with family name, initials and soldier number, while the other members of their families were just listed as spouses, sons, and daughters and in some cases as foster children or mothers of the soldiers. Birthdays of children were included, but there were no initials, and no maiden names or birthdays of wives. To make the database suitable for historical research, the passenger lists were checked against administrative records from the first years in the Netherlands and supplementary facts were included. The facts included give a sufficient starting point for historical research without revealing sensitive information about individuals' lives. In relation to each search, users are invited to fill in a form with corrections to the data or provide information about an existing portrait photograph from that time. The Moluccan users reacted enthusiastically to this invitation, and information manager Wigard tells how she received about 3000 emails in the first couple of days after the launching. During the following years, additional facts have regularly been provided by the community. The information is checked and entered by the information manager, and she also has the authority to enter persons that for some reason are not on the original lists. Examples of corrections made could be that an individual listed as a biological son was actually a foster son with another family name, or a child on the list might actually have stayed behind in Indonesia. Data on individuals, who were not within the original passenger lists, since they were stowaways hidden by their families, have also been added. Some of the information provided at the 
time of the arrival might have been too sensitive to be revealed to the Dutch authorities and in this sense knowledge that for strategic reasons had been silenced by the minority is now made part of the official, cultural memory. Thus, the richness of the database has been substantially increased by contributions from the community in question.

Since the database contains information about persons still living, each search is also, in accordance with the Dutch law on protection of person sensitive information, followed by instructions on how to secure that your personal data are made unsearchable. However, according to the information manager, so far nobody has asked to have their data hidden. On the contrary, individuals have been eager to be included. In the statement about removal of data, it is stressed that the database is created in order to help the Moluccan community search for "their roots", and so the collective value for further generations is stressed, and professional historical research is not mentioned at this point. The project the Arrival (de Aankomst) was created with respect for the source communities' painful collective memories, and as a result the Dutch-Moluccan community seems to have taken ownership of this project and embraced the idea of the database as a digital monument.

\section{Moluccan photographs in Memory of the Netherlands}

Angela Russo and Jerry Watkins have pointed out how the Web mediums' potential for digitising cultural heritage lie partly in an "ability to link institutions, other collections, and information spaces in general, rather than focusing on a specific museum collection" (2007, p. 157). In October 2004, the photo collection of MuMa was launched on the national heritage website Memory of the Netherlands (Het geheugen van Nederland), which is coordinated and hosted by the National Library of the Netherlands (Koninklijke Bibliotheek). This huge website aims to bring together a wide range of collections from the Dutch ALM institutions. At the time of writing, the website contains 88 collections from 80 institutions, and new collections are added continuously (last accessed July 20, 2010). The website is organised by themes and the photo collection from MuMa is located under History and Society in the subtheme Colonies.

On the introductory page to the collection, a colour photograph catches the eye of the user. It shows two women and a man who, based on their appearance, could all be Moluccans. They are in some public place (maybe a museum) and are bending over a table while looking at a sheet of paper with photographs. The oldest of the women is pointing something out in one of the photographs and since she is holding a pen, she might even be about to make a note next to the photograph. By choosing this picture to introduce the collection, it is emphasised how photographs are memory objects that stimulate sharing of cultural knowledge and thus are crucial for building memory communities (Kuhn, 2002). Gathering information from the source community has been an important theme in Museum Maluku's work with the photo collection, but as I will discuss below, this potential is not fully realised on the Memory of the Netherlands website. 
The collection contains 9,699 digitised photographs with metatext and is furthermore contextualised through short historical texts provided by MuMa. The photographs taken on the Moluccas cover the colonial period, the process of decolonisation, and the fight for RMS, as well as later decennials. There is a huge variety of motifs, such as, scenic views, manual labour, religious ceremonies and portraits. Photos from the Dutch context show both central historical events and everyday life of the Moluccan minority. A large part of the collection originates from private family albums and includes portraits and photographs taken at social gatherings. Thus, a user of Moluccan background browsing through the collection could come across so far unknown photographs of relatives and friends.

It is not only possible to search specifically in the Moluccan collection if a user would like to see pictures from a locality or look for persons with a particular family name, but it is also possible to search across the entire Memory of the Netherlands site. A user with interest in Dutch-Moluccan history can thus create an individual route linking memory material from other collections with the photo collection of Museum Maluku. A simple search for 'Molukkers' gives access to movie fragments, television programmes, and radio clips in the collection Moving Memory (Bewegend geheugen) provided by The Netherlands Institute for Sound and Vision (Nederlands Instituut voor Beeld en Geluid). ${ }^{6}$ The user for instance can choose to watch a movie fragment from the arrival of the boats in 1951, hear radio news about a hijacking in 1975, or watch Moluccan youth tell about their culture in a television documentary from 1984. Another user might come across very different memory materials. For instance, searching for material about the island Ambon provides a music hall song "At the bay of Ambon" (Aan de baai van Ambon), printed in Amsterdam in 1950, where a young Ambonese sings about his eternal loyalty to the Netherlands. ${ }^{7}$ The lyrics give an idea of how the fight for Moluccan independence was represented in Dutch popular culture. For a curious user, who discovers surprising links between different collections, it might be an empowering experience to create an individual pathway through the Memory of the Netherlands site, since he or she can collect specific items that would most likely not be found by any other user (Cameron \& Robinson, 2007, p. 173).

The Memory of the Netherlands website, however, is rather static in the sense that when a collection is launched on the website, it is not possible to supplement it with new items. This becomes a problem for MuMa in many ways. To begin with, the museum continuously supplements the photographic collection. Some of the new photographs add unique insights to Moluccan history, as for instance when people donate photo albums of relatives who were living in the Moluccas during colonial time. Such private collections can for instance contain old pictures from local villages. The museum is eager to make such acquisitions known to the public and especially to the Dutch-Moluccans. According to the information manager, the museum sees digitising photographs as a way of "giving back" the collection to the community from which it originates, and to the extent that photographs were made by the Dutch colonisers, this process has an element of visual repatriation (Edwards, 2003). 
Another problem with the Moluccan photo collection as presented on Memory of the Netherlands arises because it is not possible to make corrections to metadata. The metadata shown contain short descriptions of the pictures, but often names of the portrayed individuals and sometimes even the occasions on which the photographs were taken are unknown. MuMa could thus benefit from the help of the Moluccan community in order to contextualise photographs. Initially the information texts that accompanied the Moluccan photo collection on Memory on the Netherlands included an invitation to send emails with such additional information to MuMa's information manager, and she received many mails when the collection was first launched. However, the invitation to email such data has now been removed and this might be appropriate since it is not possible to change the metadata shown on Memory of the Netherlands. Feedback provided by Moluccan users will thus not become visible on the website, and this could be said to signal disregard for the cultural knowledge of the community. However, this is absolutely not the intention of Museum Maluku, which has a tradition of acknowledging and depending on the cultural memory of the community. The museum has regularly placed photographs in the Dutch-Moluccan magazine Marinjo and asked the readers to respond, and has also invited elderly Moluccans to take part in workshops in order to identify persons in photographs. Digital gathering of metadata about photographs would thus build on earlier co-collection practices at the museum.

Having the collection shown on Memory of the Netherlands, nevertheless, has been beneficial to the MuMa. The symbolic value of including the history of the Moluccan minority on this national site should not be underestimated. Moreover, MuMa might have become more visible to the broader Dutch public. Taking part in Memory of the Netherlands made it financially possible to digitise the large photo collection, and with the know-how of digitisation obtained, the museum can now digitise photographs as they are acquired. Currently, the museum is working on making the whole photographic collection visible on its own website. This has the advantage that feedback from users can be integrated, and that the photographs can be shown in connection to other types of memory material owned by the museum. I will return to these developments below.

\section{Unlocking the collections through digitisation}

As shown above, it has been an advantage for MuMa to take part in collaborative projects of digitisation that are then hosted on the websites of other national organisations. However, the museum is currently developing its own website. The ambition is to make MuMa's website the most obvious place to search for information about the Moluccan Islands and the history of the Dutch-Moluccan minority. In addition to promoting cultural events, the website is thus also used to strengthen MuMa's role as a knowledge centre. The plan is to place more historical information on the site and to provide an easy entry to the digital collection. Through an ambitions Unlocking Project (Ontsluitingsproject), it has become possible to digitise the entire collection, which contains a wide variety of memory materi- 
als of both public (i.e., press cuttings) and of a more private kind (i.e., letters and family films). ${ }^{8}$ The museum has bought an information system especially developed to manage museum collections and make them easily searchable and the interface has been adapted to the design of MuMa's website. ' From the website, the user will be able to search through all the different memory materials in the collection. Photographs and audiovisual material will be accessible through the Internet, while it will only be possible to see metadata of scanned documents. The collection of documents is so large and the museum does not have enough staff to read all documents and sort out which are of a more private character. Instead the museum has chosen a strategy of digitising everything, but restricting the access to the PDF files of documents as to only from the Intranet, since they want to ensure that personal letters, for example, are not posted out of context on the Internet. In relation to this, the information manager, Wigard, pointed out how MuMa has had to negotiate levels of access. In order to get external funding for digitising collections, museums might be asked to make whole collections accessible through the Internet, but this can be in conflict with a museum's wish to ensure ethical use. However, another reason for differential levels of access through Inter- and Intranet is MuMa's wish to attract users to the offline knowledge centre and the museum exhibitions. As pointed out by the information manager, it is important to strike a balance between creating an informative website that also makes users curious about the museum and making a website so extensive that users feel no reason to make an offline visit. Nevertheless, by searching MuMa's collections through the Internet, users can get a general overview of memory material available. Even metadata of material stored elsewhere will be included, as in the case of MuMa's recently conducted oral history project, "The Moluccan point of view in times of war" (Het Molukse perspectief in oorlogstijd"), where forty-eight elderly Moluccans in the Netherlands and in Indonesia told about their memories of wars. These interviews will be archived in a research database as part of a collection of more than $\mathbf{4 0 0}$ war testimonies that were primarily made for scientific research..$^{10}$ By making the metadata accessible through their own system, MuMa can make non-specialist users aware of the existence of these interviews and of the possibility of applying for permission to read them. In this way, the new information system of MuMa can help users to navigate through a diversity of memory materials. In addition to being searchable through MuMa's website, the information system will also be connected to a web portal about Dutch East Indies during and after the Second World War, which links collections from a variety of organisations. ${ }^{11}$ As another example of co-institutional collaboration, this increases the possibility of people with an interest in colonial history becoming aware of Moluccan cultural heritage.

Collection databases used to be an internal tool that was primarily used by museum employees, but online databases have given access to new groups of professionals as well as to non-specialist users (Cameron \& Robinson, 2007, p. 173). In the case of MuMa's own database, a high proportion of such non-specialist users is likely to have Moluccan backgrounds and might be able to add valuable contextual information about items in the col- 
lection. At the time of writing, the database has not yet been made available through the Internet and the knowledge centre's subsection of the website just informs about current projects. However, it also includes a page called Flashback, where users are invited to help contextualise photographs. It is explicitly mentioned that information provided will be "included and maintained" in the archive, and contrary to the Memory of Netherlands site, a strategy of co-collection is thus openly articulated. Users are invited to provide information via email and as with the projects described earlier, museum employees will be validating facts before they are added to the metadata. This strategy will also be used when the database becomes available on the Internet (launched in October 2010).

\section{Participation and memory politics}

The question of how digital technologies change museums' role as knowledge environments are widely discussed within museum studies (see, e.g., Cameron \& Robinson, 2007; Flinn, 2010; Srinivasan, Boast, Becvar \& Furner, 2009). The modernist paradigm that insists on museum staff's interpretative authority is challenged by a poststructuralist notion of each item in the collection having "a multiplicity of meanings and understandings attached to it" (Flinn, 2010, p. 47). Multiple voices have increasingly been incorporated in both offand on-line museum exhibitions and within recent years methods of using social web software to let users contribute to museum catalogs have been developed. Ramesh Srinivasan et al. (2009) have experimented with incorporating social software into an ethnographic catalogue of Inuit objects. They discuss how social software such as tagging, blogging, and bookmarking can be used to make room for the interpretations of source communities and thereby make engagement with the database more relevant to other users. Wikitechnology provides another possibility for enhancing a community's knowledge building, as Daniel Peacock (2010) has described in relation to Australian local historians. However, while MuMa certainly acknowledges and promotes the cultural knowledge and creativity of the Moluccan community, the information manager in relation to digitisation of the collections has chosen the more cautious approach of using asynchronous forms of interaction such as email and reaction forms (Finnemann, 2005), which does not allow users to load their information directly on MuMa's website. As already mentioned, Dutch-Moluccan history is continuously politicised and the information manager expressed concern about how to handle debate on the museum website and especially in relation to the knowledge centre. Discussions about the right interpretation of memory materials and cultural traditions could undermine the museum's intention of providing sober historical information without taking sides with any of the memory political subgroups within the community. With this background, carefully validating information before it is included might be wise, especially since research has shown how amongst non-specialist users "the belief in the inherent integrity of information a museum Web site has to offer remains a motivating factor in accessing online collections" (Cameron \& Robinson, 2007, p. 177). The rather "safe" 
approach to digital participation used by the information manager should thus not primarily be seen as a conservative insistence of the museum's role as gatekeeper of knowledge but as resulting from earnest concern about jeopardising the trust of the source community. Moreover, MuMa would have a hard time finding staff resources to monitor such direct entries and the following controversies that might arise.

Nevertheless, the museum is facing a challenge here. Getting increased access to memory materials in the collection is likely to inspire users' own performances of memory. To create a room on MuMa's website for users' creative expressions seems to be a logical follow-up to the co-collection projects described above. In a recent analysis of MuMa's permanent, offline, historical exhibition Ruben Tupamahu notes how it is primarily told on a group level and does not tell many individual life stories (2010, p. 13). An obvious choice of user generated content could thus be to encourage users to create digital scrapbooks about themselves or their relatives and therein reuse items from MuMa's digital collection as well as upload new memory materials. ${ }^{12}$ Another possibility of giving room for user voices in relation to items in MuMa's collection would be to create a blog inspired by the "Object of the Week" blog by Powerhouse Museum, Australia..$^{13}$ According to Erica Dicker (2010), such a blog can be run without being too time consuming, especially if texts are reused elsewhere in the museum's informational material. A collection blog would give a good opportunity to present exciting memory material discovered during the digitisation process and to let users inscribe meanings to these. Furthermore, blogging is in line with the way photographs have earlier been presented to the public. In order to create attention for the blog, the museum could furthermore announce new blog posts through Facebook and Twitter and thereby benefit from the push media functions of social media platforms.

From time to time, the Moluccans' situation in contemporary Dutch society as well as their historical presence is thematised in news media, theater, films and literature. And as mentioned earlier, MuMa acknowledges that the museums' representations are interpreted in relation to other texts in the broader mediascape (Sandell, 2007, p. 24). When a television movie about the train-hijacking in 1977 was previewed and discussed at MuMa before being shown on national television, the museum staff experimented with hosting a memory political debate about the film on their website. A simple comment function allowed users to upload comments and to discuss with each other. Comments were posted by Dutch-Moluccans as well as by persons with Dutch majority background, since these events are also a traumatic part of the national, cultural memory. The debate was unmonitored, but users did to some extent monitor each other in order to keep a decent tone. Both the historical events themselves and the way they were represented in the television movie were discussed, and the debate could be seen as an instance of collective memory work, understood as "an inquiring attitude towards the past and the activity of its (re)construction through memory" (Kuhn, 2002, p. 157). ${ }^{14}$ Hosting this debate was only meant as an experiment in how MuMa could facilitate co-interpretation online just as the museum is doing through offline events. It remains an open question whether it is a good idea to 
host such memory political debates on the website, or whether it gives associations to yet another Internet discussion forum and thereby threatens users' perception of the museum website's informational integrity (Cameron \& Robinson, 2007, p. 177).

The points about further participation raised above are only meant to indicate a few possibilities. MuMa's staff is still overloaded with work due to the ongoing process of digitisation, but in time the museum will surely find its own ways to increase digital co-interpretation and co-creation while still taking the sensibilities of Dutch-Moluccan memory into account.

\section{Conclusion}

In this article I have described digitisation at a small private museum specialised in the migration history of a specific ethnic minority group. Through cross-institutional collaboration and by seeking funding from national memory political programs, Museum Maluku has raised the visibility of Dutch-Moluccans as a part of Dutch national history. In building Dutch-Moluccan digital heritage, the museum has been dependent on contributions from the source community. As pointed out by Andrew Flinn, heritage institutions that encourage digital participation also recognise how users "may be more knowledgeable or have different understandings about what is being commented upon from those of professional or academic heritage workers" (2010, pp. 43-44). The projects described in this article have focused primarily on co-collection, while the museum has hesitated more when it comes to digital co-interpretation and co-creation. The use of participatory software in migration museums can surely be developed further in order to give more room for a diversity of voices within source communities. However, as a minority museum, Museum Maluku has a long tradition of fruitful collaboration with the source community and has acquired expertise in taking memory politics into consideration. The case of Museum Maluku exemplifies how projects that digitise migration heritage must be thoughtfully implemented since migration memories are often contested and politicised both within the source communities and in the broader public sphere.

\section{References}

Cameron, F. \& Robinson, H. (2007). Digital knowledgescapes: Cultural, theoretical, practical, and usage issues facing museum collection databases in a digital epoch. In F. Cameron \& S. Kenderdine (Eds.), Theorizing digital cultural heritage (pp. 165-191). Cambridge, Mass.: MIT Press.

Dicker, E. (2010, March 31). The impact of blogs and other social media on the life of a curator. In J. Trant and D. Bearman (Eds.) Museums and the Web 2010: Proceedings. Toronto: Archives \& Museum Infomatics. Retrieved June 2, 2010, from http://www.archimuse.com/mw2010/papers/dicker/dicker.html. 
Edwards, E. (2003). Talking Visual Histories: Introduction. In L. Peers \& A.K. Brown (Eds.), Museums and source communities: A Routledge reader (pp. 83-99) London \& New York: Routledge.

Finnemann, N. O. (2005). Internettet i mediehistorisk perspektiv [The internet in media historical perspective], Frederiksberg: Samfundslitteratur.

Flinn, A. (2010). Independent community archives and community-generated content: 'Writing, saving and sharing our histories'. Convergence: The International Journal of Research into New Media Technologies, 16(1): 39-51.

Kress, G. \& van Leeuwen, T. (2006). Reading Images: The Grammar of Visual Design: Second Edition. London \& New York: Routledge.

Kuhn, A. (2002). Family secrets: Acts of memory and imagination, New edition. London: Verso.

Levitt, P. \& Glick Schiller, N. (2004) Conceptualizing simultaneity: A transnational social field perspective on society. International Migration Review, 38(3): 1002-1039.

Lilipaly-de Voogt, A. (1993). De boom vol schatten: vertellingen uit de Molukken. [The tree filled with treasures: stories from the Moluccas]. Utrecht: Steunpunt Edukatie Molukkers/Zuidwolde: Het Drentse Boek.

Peacock, D. (2010, March 31). Putting Mallala on the map: Creating a Wiki community with now and then. In J. Trant and D. Bearman (Eds). Museums and the Web 2010: Proceedings. Toronto: Archives \& Museum Informatics. Retrieved August 9, 2010. http://www.archimuse.com/mw2010/papers/peacock/peacock.html.

Peers, L. \& Brown A.K. (2003): Introduction. In L. Peers \& A.K. Brown (Eds.): Museums and source communities: A Routledge Reader (pp. 1-16) London \& New York: Routledge.

Russo, A. \& Watkins, J. (2007). Digital cultural communication: Audience and remediation. In F. Cameron and S. Kenderdine (Eds.): Theorizing digital cultural heritage (pp.149-163). Cambridge, Mass.: MIT Press

Sandell, R. (2007). Museums, prejudice and the reframing of difference. London \& New York: Routledge.

Smeets, H. \& Steijlen, F. (2006): In Nederland gebleven: De geschiedenis van Molukkers 1951-2006 [Remained in the Netherlands: The history of Moluccans 1951-2006]. Amsterdam/Utrecht: Publisher Bert Bakker/Moluks Historisch Museum.

Srinivasan, R., Boast. R. Becvar, K.M. \& Furner, J. (2009). Blobgects: Digital museum catalogs and diverse user communities. Journal of the American Society for Information Science and Technology, 60 (4): 666-678

Stevens, Mary (2007). Museums, minorities and recognition: memories of North Africa in contemporary France. Museum and Society, 5(1): 29-43

Tupamahu, T.R. (2010). Migrantenerfgoed in het Nationaal Historisch Museum. Bijdragen van postkoloniale migranten (Molukse Nederlanders) en arbeidsmigranten (Turkse en Marokkaanse Nederlanders) vergeleken) [Migrant heritage in the National Historical Museum. Contributions from postcolonial migrants (Moluccan Dutchmen) and labour migrants (Turkish and Moroccan Dutchmen). Master thesis. Retrived July 29, 2010, from University of Utrecht: http://studenttheses.library.uu.nl/search. php? language $=$ nl\&gry $=$ tupamahu.

Walkowitz. D.J. (2009). Ellis Island redux: The imperian turn and the race of ethnicity. In D. J. Walkowitz and L.M. Knauer (Eds.). Contested histories in public space: Memory, race, and nation. Durham \& London: Duke University Press.

\section{Notes}

1. The article is based on my own examination of MuMa's Web projects as well as on information obtained through qualitative interviews and extensive email correspondence with the museum's information manager, Nanneke Wigard. The article is written as part of the research project Changing Borderlines: 
Mediatisation and Cultural Citizenship, supported by the Danish Council for Independent Research (Culture and Communication). The author would like to thank Nanneke Wigard for her friendly help.

2. This paragraph gives a brief introduction to the history of the Moluccan minority based on Henk Smeets and Fridus Steilen (2006).

3. Mission and vision statements at the museum website (www.museum-maluku.nl, accessed July 29 2010).

4. The possibility of searching for passengers and pictures of ships are highly popular features on the website of Ellis Island Museum (Walkowitz, 2009).

5. The database De aankomst is hosted by the Dutch National Archive and was launched in March 2004 www.nationaalarchief.nl/aankomst/ (accessed June 13, 2010).

6. The Netherlands Institute for Sound and Vision is the primary collector of Dutch audio-visual heritage including national broadcasting archives, portal.beeldengeluid.nl (accessed June 13, 2010).

7. This item was provided by The Netherlands Theatre Institute (Theater Instituut Nederland).

8. This project became possible due to a grant from the trust the Gesture (Stichting Het Gebaar), which was meant as a conciliatory gesture from the Dutch government towards citizens who experienced Second World War and the postwar period in the Dutch East Indies. The foundation was financed by the Dutch Ministry of Health, Welfare and Sport.

9. The information system was provided by Adlib (http://www.adlibsoft.com/).

10. The programme Heritage from the War (Erfgoed van de Oorlog), initiated and financed by the Dutch Ministry of Health, Welfare and Sport, ran from 2007-2009 and aimed at collecting heritage from the Second World War and stimulating the use of the collected memory material. The sub-programme Telling Witnesses (Getuigen Verhalen) subsidised a variety of oral history projects.

11. This web portal has also been realised as part of the programme Heritage from the War (Erfgoed van de Oorlog), and is run by the Dutch East Indies Memory Centrum Bronbeek (Indisch Herinneringscentrum Bronbeek (IHCB), (http://www.indieinoorlog.nl/oorloginindie/oorloginindie/elements/index. jsp, accessed July 212010 ).

12. A similar strategy was used on the website Moving here: 200 years of migration to England (www.movinghere.org.uk), discussed in Flinn (2010).

13. Discussed by Erica Dicker (2010), can be seen at (http://www.powerhousemuseum.com/collection/ blog).

14. The movie de Punt was previewed on MuMa on April 26, 2009 and had a premiere on national television on May 14, 2010. The web debate became quite intense and went on for a couple of weeks. By May 14, 2010, it had reached 663 comments. It is beyond the scope of this article to make a thorough analysis of the debate, but this is planned as part of my current research project. (Debate accessed January 4, 2010)

Randi Marselis, PhD 